\title{
Advertising rules change - page charges inevitable?
}

P ulsus Group Inc will celebrate its 30th anniversary in 2014. With a vision to publish, promote and disseminate the work of medical researchers in a manner that exemplifies the highest standards in research integrity, we have successfully established more than 10 Canadian journals. The first, The Canadian Journal of Cardiology, was sold to the Canadian Cardiovascular Society and is currently being published by a non-Canadian multinational. Today, we continue to publish six journals, all official publications of their respective Canadian medical societies. Each society receives a portion of revenues derived from the Journal. This includes Pain Research $\mathbb{E}$ Management, the official journal of the Canadian Pain Society, which is in its 18 th year of publication.

During these 18 years, we have published hundreds of studies serving the Canadian and international research communities, and the Canadian physicians who receive the Journal free of charge. It also serves advertisers well by providing access to specialists and general practitioners with an interest in this therapeutic area. Our business model has been symbiotic on many levels, with the publication of research being mainly supported by the pharmaceutical industry, which in turn benefits by increasing exposure to its products. This model, however, is in danger of unravelling...

First, advertising support from pharmaceutical companies has decreased significantly over the past several years. And now, a second threat has appeared on the horizon. Currently, all advertisements aimed at Canadian physicians must be precleared by the Pharmaceutical Advertising Advisory Board (PAAB) and carry its logo, a process financed almost entirely by Canada's research-based pharmaceutical companies $(\mathrm{Rx} \& \mathrm{D})$. Recently, PAAB, on an initiative of $\mathrm{Rx} \& \mathrm{D}$, voted to replace all prescribing information (PI) with a combination of 'fair balance' (on the face of an advertisement or in close proximity) and a link to the online product monograph. This comes into effect for all new advertisements precleared as of July 2013, but there will be a one-year transition period in which both old-format ads (PI) and newformat ads (link to product monograph) will run.

Given the loss of PI (estimated at $30 \%$ of advertising revenues), we will be required to make significant changes to the Journal business model. Changes under consideration include increasing the cost of advertising, decreasing distribution of the print copy and/or the establishment of a pay-to-publish model, whereby authors are charged to publish their work, allowing for immediate open access. Currently, Pulsus Group has two Journals that have successfully implemented this model and are financed largely by page charges.

We admit to being perplexed with this lack of advertising support from industry, the elimination of PI (leaving readers without immediate access to this important information) and Health Canada's sanction of this new model, but have worked diligently to be prepared for all eventualities. We have also re-launched the Journal website (www.pulsus.com) with many new attributes including an 'In Press' section, which will hold articles awaiting print or online publication, and can be accessed by Society members and subscribers.

We will move forward with our mission and urge pharmaceutical companies to continue in their critical role of advertising in peerreview journals to support the dissemination of medical research. After all, unpublished research serves no one...

Robert B Kalina

Publisher 


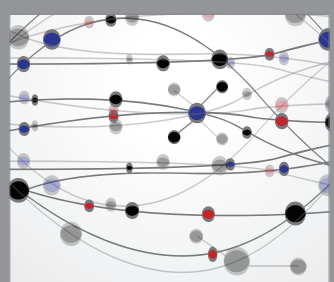

The Scientific World Journal
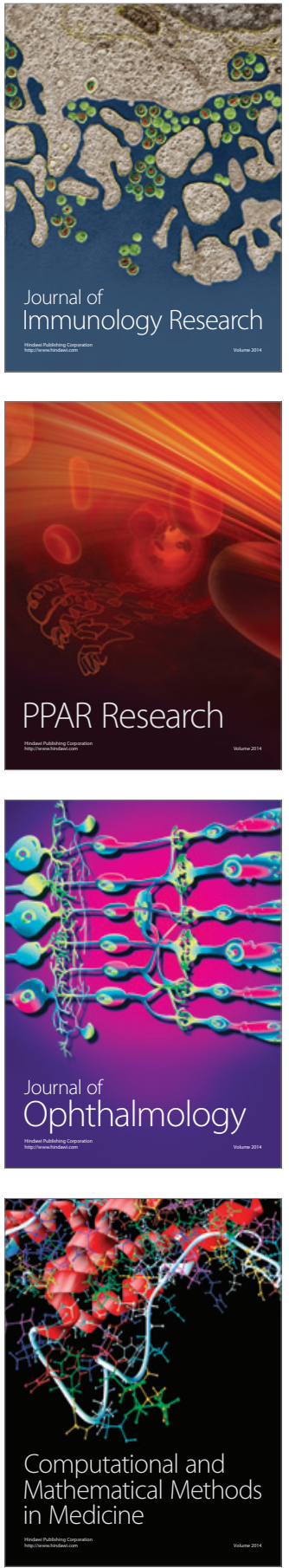

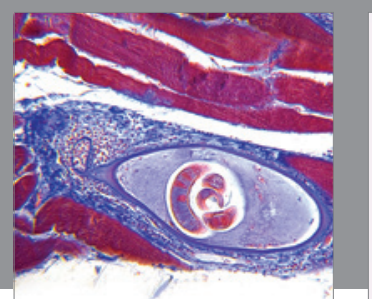

Gastroenterology Research and Practice

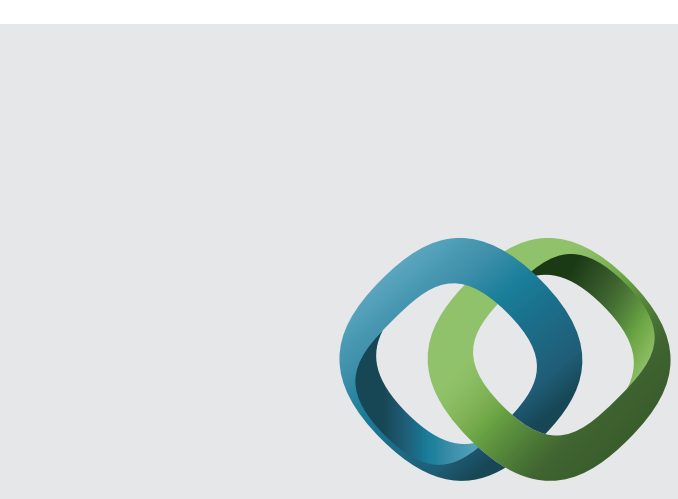

\section{Hindawi}

Submit your manuscripts at

http://www.hindawi.com
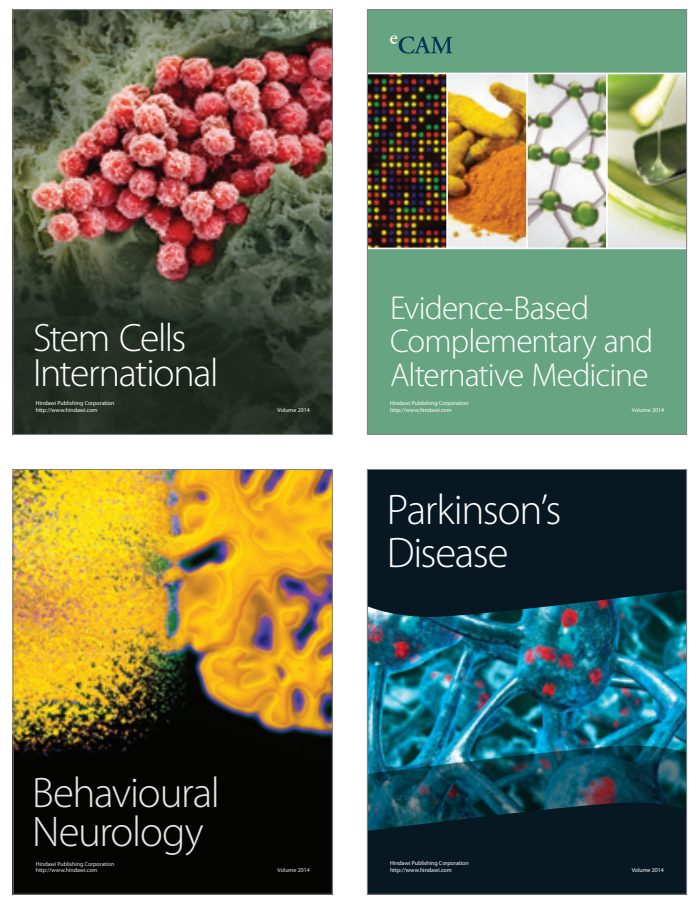
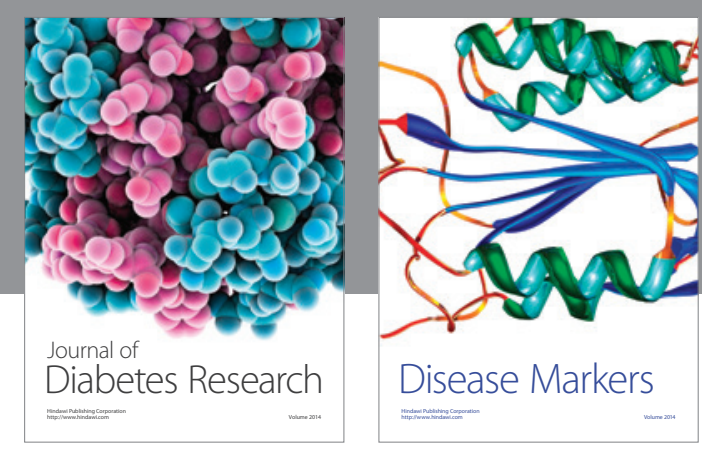

Disease Markers
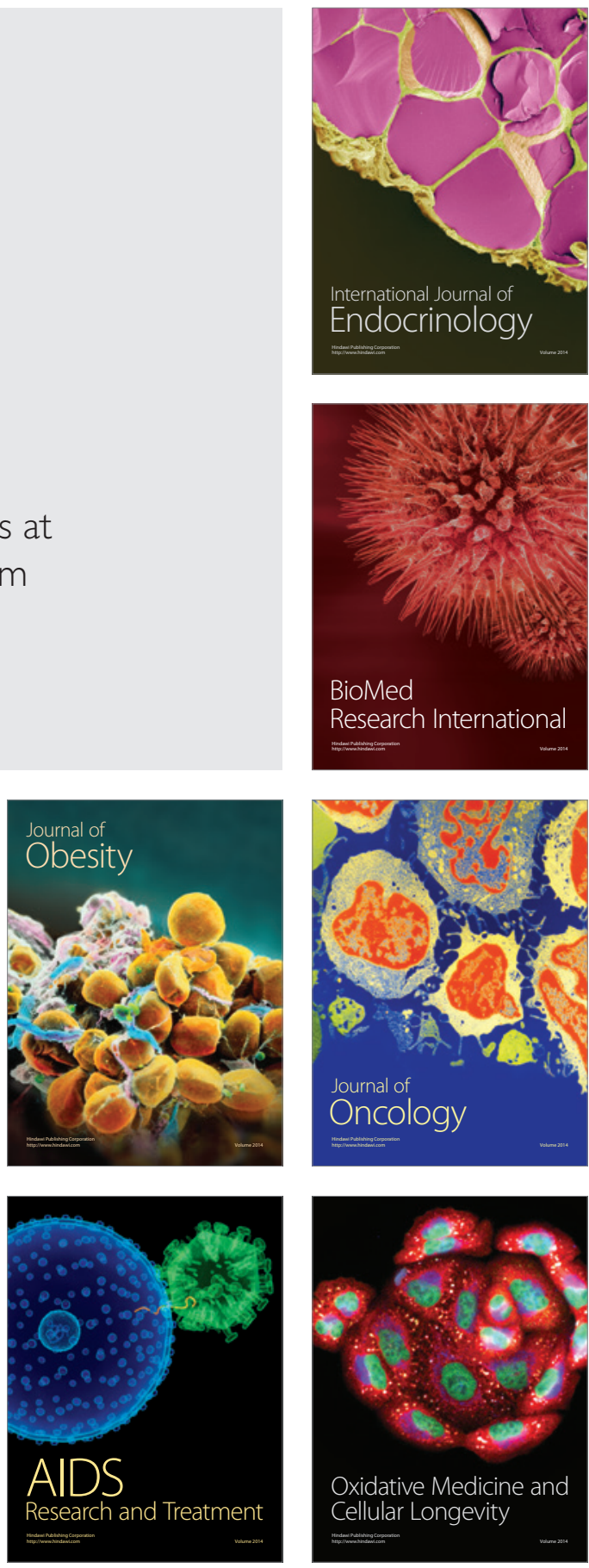